Polymer Journal, Vol. 39, No. 11, pp. 1122-1127 (2007)

(C) 2007 The Society of Polymer Science, Japan

\title{
pH Responsive Aggregation of Imidazolium Cations-Modified Gold Nanoparticles with Poly(acrylic acid) in Aqueous Solution
}

\author{
Kensuke NAKA, ${ }^{\dagger}$ Hiroyuki TANAKA, and Yoshiki CHUJO ${ }^{\dagger}$ \\ Department of Polymer Chemistry, Graduate School of Engineering, Kyoto University, \\ Katsura, Nishikyo-ku, Kyoto 615-8510, Japan
}

(Received June 14, 2007; Accepted July 22, 2007; Published September 7, 2007)

\begin{abstract}
We report $\mathrm{pH}$-responsive control of the colloidal dispersions of imidazolium cations-modified gold nanoparticles by using poly(acrylic acid) (PAA). The gold nanoparticles were precipitated when PAA $\left(M_{\mathrm{w}}=25000\right)$ was added in aqueous solution of which $\mathrm{pH}$ was 2.4. The precipitate was redissolved when the solution's $\mathrm{pH}$ dropped below pH 1.9 and rose above $\mathrm{pH}$ 5.5. According to UV-visible spectra, transmission electron microscopy (TEM) observations, and dynamic light scattering (DLS) analysis, it is indicated that the gold nanoparticles at lower $\mathrm{pH}$ $(\mathrm{pH}<1.9)$ were well redispersed in aqueous solution and aggregates with a diameter of $115 \pm 21 \mathrm{~nm}$ of the gold nanoparticles were formed at above $\mathrm{pH}$ 5.5. Effect of molecular weights of PAA was also studied.
\end{abstract}

[doi:10.1295/polymj.PJ2007075]

KEY WORDS Gold Nanoparticle / Poly(acrylic acid) / pH-Responsive / N-Methylimidazolium / Nanoparticles-Based Flocculation /

Metal nanoparticles have various unusual chemical and physical properties compared with those of metal atoms or bulk metal due to the quantum size effect and their large superficial area, which make them attractive for applications such as optics, electronics, catalysis and biology. ${ }^{1,2}$ In recent years, controlled colloidal dispersions of the metal nanoparticles by using various stimuli, such as $\mathrm{pH}$, temperature, light and so on, have been received much attention. ${ }^{3-6}$ Since the properties of the metal nanoparticles are largely depending on their aggregated states, a responsive aggregation system is valuable for sensing materials. In particular, $\mathrm{pH}$-responsive system in aqueous solution has extremely promising prospect. Many biological phenomena, e.g. cellular recognition and transportation in tissues and organs, are largely concerned to $\mathrm{pH}$ at which they occur. There have been several reports for $\mathrm{pH}$-responsive metal nanoparticles. ${ }^{7-11}$ Toshima and co-workers synthesized 3-mercaptopropionic acid-modified gold nanoparticles and reversibly controlled the colloidal dispersions by using interparticle hydrogen bonds or electrostatic repulsion depending on $\mathrm{pH} .{ }^{7}$ Lee and co-workers synthesized gold nanoparticles coated by a hydrogel consisted of poly(acrylic acid-co- $N$-isopropyl acrylamide) and acted as a interrupter of surface plasmon absorbance depending on $\mathrm{pH}$ and temperature. ${ }^{8}$

Recently, we have first time prepared gold nanoparticles modified with $\mathrm{N}$-methylimidazolium chloride (MImCl-AuNP) and reported their aggregation by anion exchange of the imidazolium salts on the surface of the gold nanoparticles. ${ }^{6} \mathrm{~N}$-Alkylimidazolium salts are attracting much interest in many fields of chemistry and industry as ionic liquids due to their unique properties, such as environmentally benign characteristic, highly thermal stability, non-volatile and high ionic conductivity. ${ }^{12,13}$ The $\mathrm{C} 2$ hydrogen on the imidazolium cation is acidic and an anion associates strongly to the imidazolium cation compared with a pyridinium cation or a quaternary ammonium cation. ${ }^{14}$ Here we describe pH-responsive control of the colloidal dispersions of MImCl-AuNP using a combination of poly(acrylic acid) (PAA) in aqueous solution. The strategy is based on the electrostatic interaction between the imidazolium cations on the surface of the gold nanoparticles and the carboxylate anions of PAA. There are several reports for phenomena of nanoparticles-based flocculation by charged polymers. ${ }^{15-21}$ Although extensive experimental and theoretical works are reported to understanding the flocculation processes and construct nanoparticlesbased flocculated materials with controlled structures, studies for $\mathrm{pH}$-responsive phenomena of nanoparticles-based flocculated materials were limited. Segal et al. reported a precipitation-redispersion mechanism for complexation of short chain PAA with cerium oxide nanoparticles. ${ }^{21}$ They showed that addition of PAA to a cerium oxide sols leads to macroscopic precipitation and the solution redispersed into a clear solution of single particles with an anionic PAA corona as the $\mathrm{pH}$ increased. In the present report, we found a different precipitation-redispersion behavior for the complexes of the imidazolium cations-modified gold nanoparticles with PAA.

${ }^{\dagger}$ To whom correspondence should be addressed (Tel: +81-75-383-2607, Fax: +81-75-383-2607, E-mail: ken@chujo.synchem.kyoto-u.ac.jp). 


\section{EXPERIMENTAL}

\section{Measurements}

${ }^{1} \mathrm{H}$ NMR spectra were obtained with a JOEL EX400 spectrometer $(400 \mathrm{MHz})$. UV-visible spectra were measured on a JASCO V-530 spectrophotometer using quartz cuvettes with a $1 \mathrm{~cm}$ optical path length. Transmission electron microscopy (TEM) was performed using a JOEL JEM-100SX operated at 100 $\mathrm{kV}$ electron beam accelerating voltage. One drop of the solution of the sample was deposited onto a copper grid and the excess of the dropped solution was blotted off the grid with a filter paper, and then the sample was dried under ambient conditions. Thermogravimetric analysis (TGA) was performed using a TG/ DTA6200, SEIKO Instruments, Inc. with the heating rate of $10^{\circ} \mathrm{C} \mathrm{min}^{-1}$ up to $900^{\circ} \mathrm{C}$ under air. FT-IR spectra were recorded on a Perkin Elmer 1600 infrared spectrophotometer using a $\mathrm{KBr}$ disk dispersed with the powder sample. Dynamic light scattering (DLS) was measured on a FPAR-1000, Otsuka Electronics Co., Ltd. $\mathrm{pH}$ measurements were performed using a $\mathrm{pH}$ meter D-21, HORIBA, Ltd.

\section{Materials}

Poly(acrylic acid)s $\left(M_{\mathrm{w}}=5000,25000\right.$, and 250000 $\mathrm{g} \mathrm{mol}^{-1}$ ) were purchased from Wako Pure Chemical Industries, Ltd. Poly(acrylic acid) $\quad\left(M_{\mathrm{w}}=2000 \mathrm{~g}\right.$ $\mathrm{mol}^{-1}$ ) was purchased from Aldrich Chemical Co. Poly(styrenesulfonic acid) $\left(M_{\mathrm{w}}=70000 \mathrm{~g} \mathrm{~mol}^{-1}\right)$ was purchased from Polyscience. The other reagents and solvents were used as supplied, unless stated otherwise.

Imidazolium Cations-Modified Gold Nanoparticles $(\mathrm{MImCl}-\mathrm{AuNP})$. A procedure was described in our previous paper. ${ }^{6}$ The average diameter of the gold nanoparticles was $4.8 \pm 0.6 \mathrm{~nm}$ as measured by a TEM image by averaging the size of 100 particles. This was well in accordance with a dynamic light scattering (DLS) result $(5.2 \pm 0.8 \mathrm{~nm})$ of MImClAuNP in aqueous solution. The organic content of MImCl-AuNP was $17.2 \mathrm{wt} \%$ from a thermogravimetric analysis (TGA). The number of the imidazolium cations adsorbed on the surface of the each gold nanoparticle was calculated as 610 based on the fact that the average particle size is $4.8 \mathrm{~nm}$.

\section{Addition of PAA to Aqueous Solution of MImCl-AuNP}

A typical procedure is described as follows. In a $20 \mathrm{~mL}$ sample bottle, the aqueous solution $(5 \mathrm{~mL})$ of MImCl-AuNP $\left(0.5 \mathrm{mg}\right.$, containing $3.7 \times 10^{-4} \mathrm{mmol}$ of the imidazolium units calculated from the TGA result) was prepared. To this solution, an aqueous solution $(5 \mathrm{~mL})$ of PAA $\left(M_{\mathrm{w}}=25000\right)(200 \mathrm{mg}, 2.8 \mathrm{mmol}$ of a repeating unit) was added with vigorously stirring. For studying the $\mathrm{pH}$ effect on the precipitates, the suspension was acidified with $1.0 \mathrm{M} \mathrm{HCl}$ and neutralized with $1.0 \mathrm{M} \mathrm{NaOH}$.

\section{RESULTS AND DISCUSSION}

When $200 \mathrm{mg}$ of PAA $\left(M_{\mathrm{w}}=25000\right)$ was added to an aqueous solution of MImCl-AuNP $(0.5 \mathrm{mg})$, a red color of the solution gradually disappeared. After stirring for $6 \mathrm{~h}$, a precipitate was observed with a clear colorless supernatant. The colorless supernatant indicates that all the gold nanoparticles were comprised in the precipitate. The $\mathrm{pH}$ of the solution was 2.4. After washing the precipitate several times by an acidic aqueous solution adjusted to $\mathrm{pH} 2.4$ by $\mathrm{HCl}$ to remove extra PAA, we performed TGA and FT-IR measurements of the precipitate. TGA results showed that the organic components in the gold nanoparticles and the precipitates were $17.2 \mathrm{wt} \%$ and $28.9 \mathrm{wt} \%$, respectively. The FT-IR measurement showed the peaks of $\mathrm{C}=\mathrm{O}$ stretching vibration derived from the carboxylic acid units $\left(1698 \mathrm{~cm}^{-1}\right)$ and the carboxylate anion units $\left(1551 \mathrm{~cm}^{-1}\right)$ in addition to the peak at 1636 $\mathrm{cm}^{-1}$ derived from the $\mathrm{C}=\mathrm{C}$ stretching vibration of the imidazolium cations (Figure 1). The presence of the carboxylate anion in the precipitates after washing by the acidic aqueous solution adjusted to $\mathrm{pH} 2.4$ indicates that the counter anion of the imidazolium cation was exchanged from chloride to the carboxylate anion of PAA. The molar ratio of the carboxylate unit to the imidazolium cation in the precipitate was calculated as 3.1 from the TGA results. From these observations, the precipitate was formed by the electrostatic interaction between MImCl-AuNP and PAA. Addition of glutaric acid (equal mol of a carboxylic unit to that in the case of PAA) instead of PAA $\left(M_{\mathrm{w}}=25000\right)$ to the aqueous solution of MImCl-AuNP caused no precipitate.

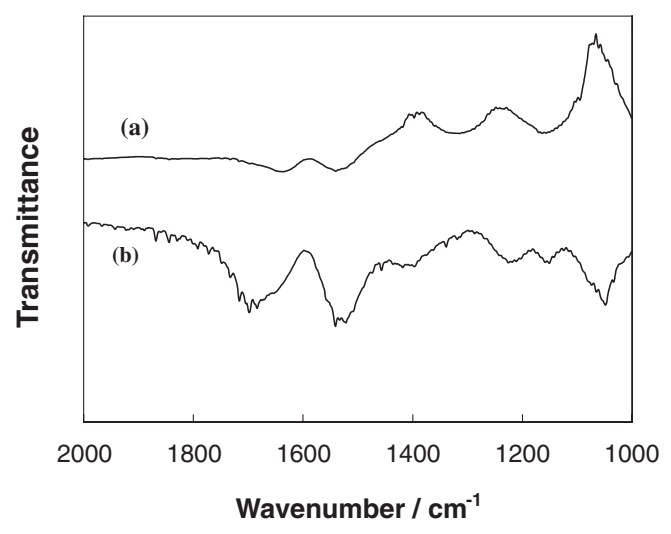

Figure 1. FT-IR spectra of MImCl-AuNP (a) and the precipitates after mixing MImCl-AuNP and PAA $\left(M_{\mathrm{w}}=25000\right)(\mathrm{b})$. 


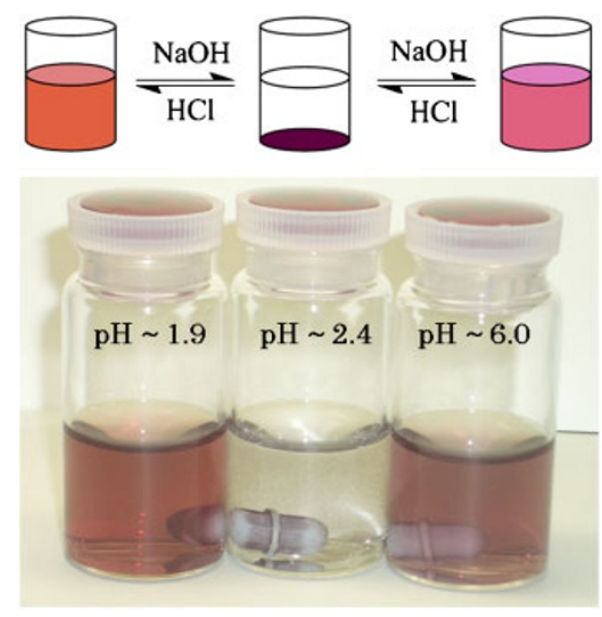

Figure 2. Photograph of various $\mathrm{pH}$ solutions of $\mathrm{MImCl}-$ AuNP with PAA $\left(M_{\mathrm{w}}=25000\right)$.

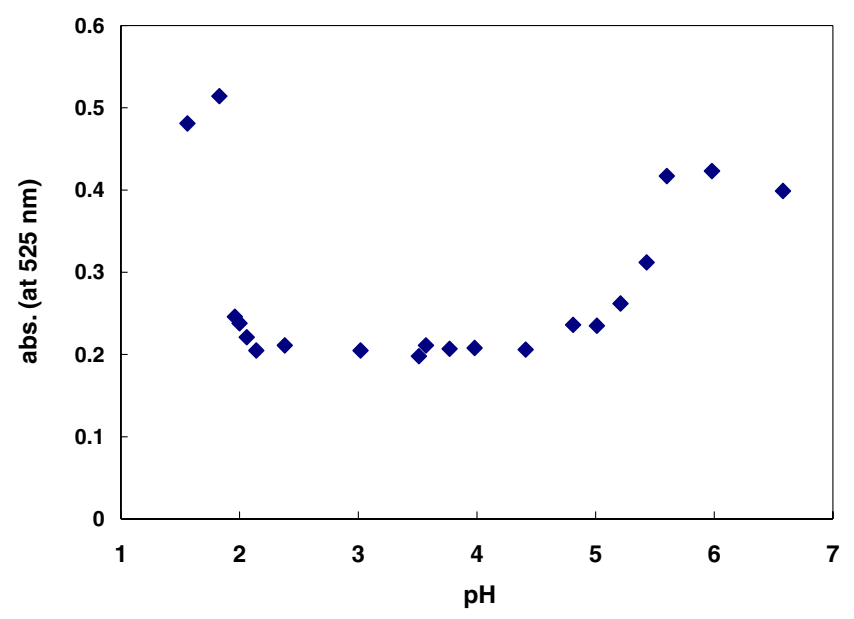

Figure 3. UV-vis absorption intensity at $525 \mathrm{~nm}$ of aqueous solution of MImCl-AuNP with PAA $\left(M_{\mathrm{w}}=25000\right)$ at various $\mathrm{pH}$.

The resulting precipitate after MImCl-AuNP was mixed with PAA $\left(M_{\mathrm{w}}=25000\right)$ in aqueous solution as described above was dissolved into a clear red colored solution when the $\mathrm{pH}$ dropped below 1.9 by addition of $1.0 \mathrm{M} \mathrm{HCl}$. Addition of $1.0 \mathrm{M} \mathrm{NaOH}$ to the acidified solution caused a precipitate again at the $\mathrm{pH}$ of 2.2, and the precipitate was redissolved when the $\mathrm{pH}$ rose above 5.5 (Figure 2). Addition of $1.0 \mathrm{M}$ $\mathrm{HCl}$ to the final solution reproduced the precipitation-redispersion process until the $\mathrm{pH}$ dropped below 1.9. Figure 3 shows the plot of the UV-vis absorption intensity at $525 \mathrm{~nm}$ of the aqueous solution of MImClAuNP with PAA $\left(M_{\mathrm{w}}=25000\right)$ against the $\mathrm{pH}$. The UV-vis absorption maxima of the surface plasmon absorption of MImCl-AuNP at the pH of 6.0 and 1.7 were 528 and $516 \mathrm{~nm}$, respectively (Figure 4). The absorption maximum of the solution at $\mathrm{pH} 6.0$ was redshifted compared with that in the case of the solution at $\mathrm{pH} 1.7$ and the pristine solution of MImCl-AuNP without PAA $\left(\lambda_{\max }=514 \mathrm{~nm}\right)$. The red shift can be

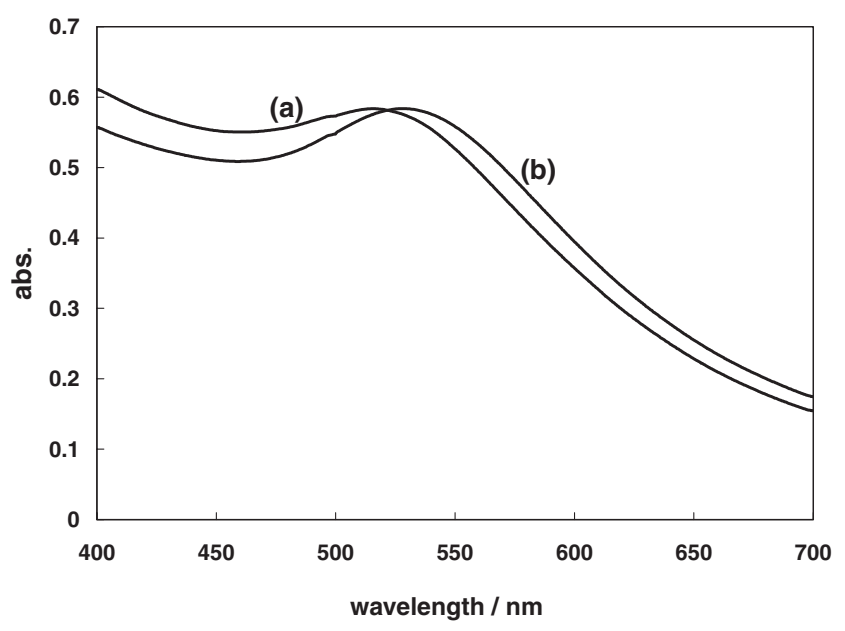

Figure 4. UV-vis absorption spectra of the solutions of MImCl-AuNP with PAA $\left(M_{\mathrm{w}}=25000\right)$ (a) at $\mathrm{pH} 1.5$ and (b) at pH 6.0.

attributed to the coupled plasmon absorbance of the gold nanoparticles in closer contact, ${ }^{3}$ which indicates a formation of particle aggregates in the aqueous solution at $\mathrm{pH}$ 6.0. The addition of $\mathrm{NaCl}(4 \mathrm{mmol})$ to the aqueous solution of MImCl-AuNP in the presence of PAA at $\mathrm{pH} 6.0$ gave no change of the surface plasmon absorption. The aggregate formation was supported by a TEM observation and a DLS measurement. The TEM image of MImCl-AuNP in the presence of PAA at pH 1.7 indicates the dispersed state of the gold nanoparticles as well as before the addition of PAA (Figure 5a). The TEM image of the sample at $\mathrm{pH} 6.0$ shows the aggregates of the gold nanoparticles and the size of the aggregates was ranging from $40 \mathrm{~nm}$ to $150 \mathrm{~nm}$ (Figure $5 \mathrm{~b}$ ). A DLS measurement suggested the formation of the aggregates in aqueous solution with a diameter of $115 \pm 21 \mathrm{~nm}$.

Decrease the addition amount of PAA $\left(M_{\mathrm{w}}=\right.$ $25000)$ to $100 \mathrm{mg}$ ( $1.4 \mathrm{mmol}$ of the repeating unit) showed the same phenomenon observed as described above. However, further reduced the amount of PAA $\left(M_{\mathrm{w}}=25000\right)$ to $50 \mathrm{mg}(0.7 \mathrm{mmol}$ of the repeating unit), no precipitate formed even after $36 \mathrm{~h}$ incubation. Although no precipitate was formed, the UVvis absorption spectrum of the solution shows the surface plasmon absorption at $525 \mathrm{~nm}$, which indicates an aggregate formation.

We studied the effect of the molecular weight of PAA. When $200 \mathrm{mg}$ of PAA $\left(M_{\mathrm{w}}=5000\right)$ was added to the solution of the gold nanoparticles, a precipitate was observed after stirring for only $10 \mathrm{~min}$, which was significantly faster than the case of the addition of PAA $\left(M_{\mathrm{w}}=25000\right)$ as described above. Precipitate formation was observed less than 1 min after addition of $200 \mathrm{mg}$ of PAA $\left(M_{\mathrm{w}}=2000\right)$. In contrast, the addition of $200 \mathrm{mg}$ of PAA $\left(M_{\mathrm{w}}=250000\right)$ caused no pre- 
(a)

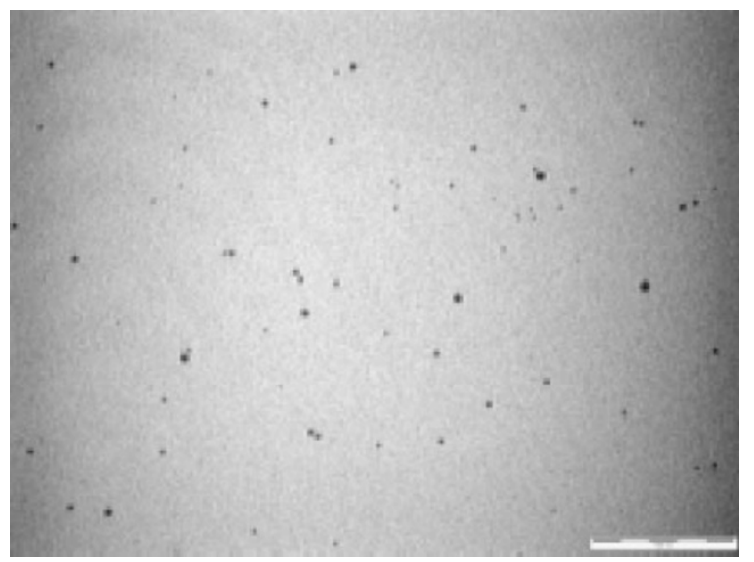

(b)

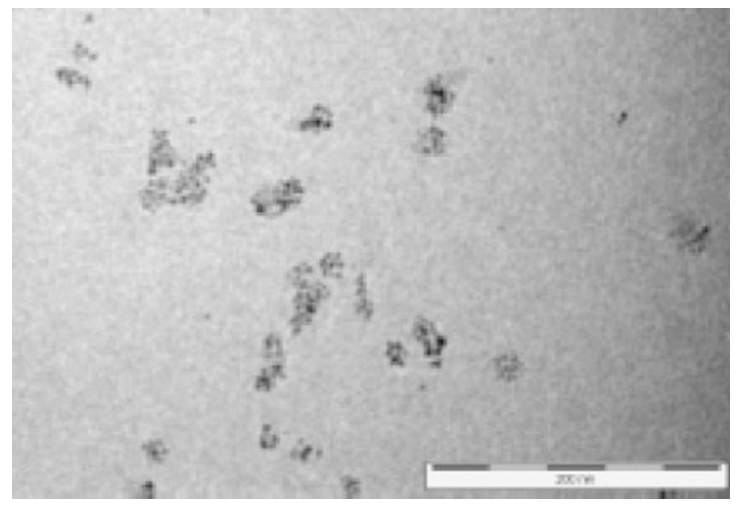

(c)

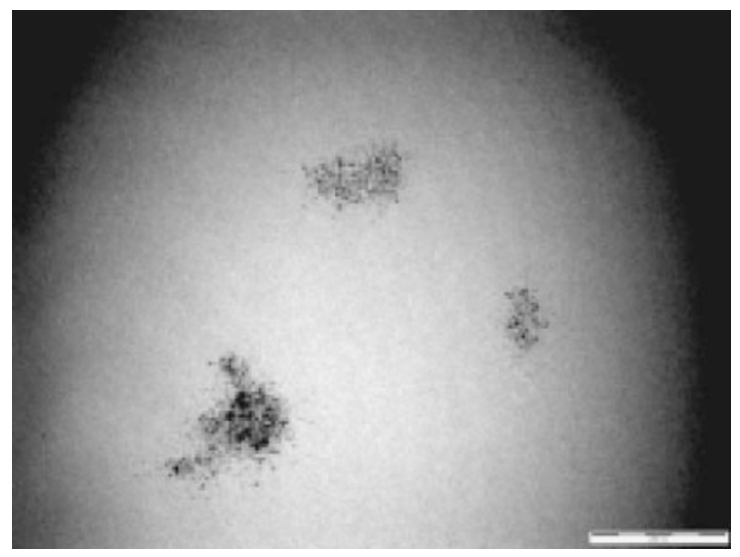

Figure 5. TEM images of MImCl-AuNP with PAA $\left(M_{\mathrm{w}}=\right.$ 25000) (a) at pH 1.5 (scale bar: $100 \mathrm{~nm}$ ) and (b, c) at pH 6.0 (scale bars: $200 \mathrm{~nm}$ ).

cipitation even after 2 months. A DLS measurement of this solution, however, indicated the formation of the aggregates with a diameter of $174 \pm 29 \mathrm{~nm}$. The TGA results of the obtained precipitates after the addition of the various molecular weights of PAA and washing by the acidic aqueous solution suggest that the organic contents of the obtained precipitates were independent of the molecular weights of PAA (Table I). The molar ratios of the carboxylate unit to
Table I. Results of the precipitates of the gold nanoparticles after addition of PAA

\begin{tabular}{rccc}
\hline $\begin{array}{c}M_{\mathrm{w}} \text { of PAA } \\
\left(\mathrm{g} \mathrm{mol}^{-1}\right)\end{array}$ & $\begin{array}{c}\text { Observed } \\
\text { precipitation time }\end{array}$ & $\begin{array}{c}\text { Weight loss } \\
(\mathrm{wt} \%)\end{array}$ & $\begin{array}{c}\text { Number of PAA } \\
\text { chain per AuNP }\end{array}$ \\
\hline 2000 & $1 \mathrm{~min}$ & 28.7 & 5.3 \\
5000 & $10 \mathrm{~min}$ & 30.8 & 33 \\
25000 & $6 \mathrm{~h}$ & 28.9 & 67 \\
250000 & no & - & - \\
\hline
\end{tabular}

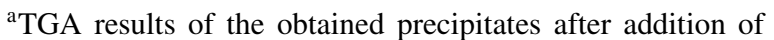
various molecular weights of PAA. ${ }^{\mathrm{b}}$ The calculated number of PAA chain per one gold nanoparticle in the precipitates.

the imidazolium cation in the precipitates were calculated as 3.1 to 3.7 . If all the imidazolium cations interacted with the carboxylate anions, approximately $70 \mathrm{~mol} \%$ of the carboxylate units of PAA might be not interacting with the gold nanoparticles. Table I also shows the calculated numbers of the polymer chains tangling per gold nanoparticle in the precipitates. In the case of PAA $\left(M_{\mathrm{w}}=25000\right), 5$ polymer chains tangled per gold nanoparticle. In the case of PAA $\left(M_{\mathrm{w}}=2000\right), 67$ polymer chains tangled per gold nanoparticle. Longer chain PAA has a longer non-interacted chain with the gold nanoparticle than that of shorter chain PAA. Existence of the longer non-interacted chains on the nanoparticles promotes the solubility of the nanoparticles. The behavior of the $\mathrm{pH}$-response of the precipitate after the addition of PAA $\left(M_{\mathrm{w}}=5000\right)$ was similar to that after the addition of PAA $\left(M_{\mathrm{w}}=25000\right)$. The precipitate after the addition of PAA $\left(M_{\mathrm{w}}=2000\right)$ was un-redissolved even after addition of $1.0 \mathrm{M} \mathrm{NaOH}$. We assumed that this difference also derives from the short chain PAA $\left(M_{\mathrm{w}}=2000\right)$. In the case of PAA $\left(M_{\mathrm{w}}=2000\right)$, the short non-interacted carboxylate units might diminish the electrostatic repulsion for the redissolution.

The proposed mechanism for the $\mathrm{pH}$-responsive phenomena is as follows (Figure 6). After addition of PAA to the aqueous solution of MImCl-AuNP, the counter anion of the imidazolium cation was exchanged from chloride to the carboxylate anion of PAA and interpolymer hydrogen-bondings of the remaining carboxylic acids formed the precipitate. When the $\mathrm{pH}$ of the solution dropped below 1.9 by addition of $\mathrm{HCl}$, the protonation of the carboxylate units of PAA in the precipitates promotes the anion exchange of the imidazolium cations to chloride. Thus, the gold nanoparticles redispersed independently of the presence of PAA as before the addition of PAA. When the $\mathrm{pH}$ rose above 5.5 by addition of $\mathrm{NaOH}$, the polymer backbones are electrostatically repulsive each other. It was well known that conformation of the anionic polymer, such as PAA, dramatically depending on $\mathrm{pH}$ in an aqueous solution. ${ }^{22-24}$ As a result, 


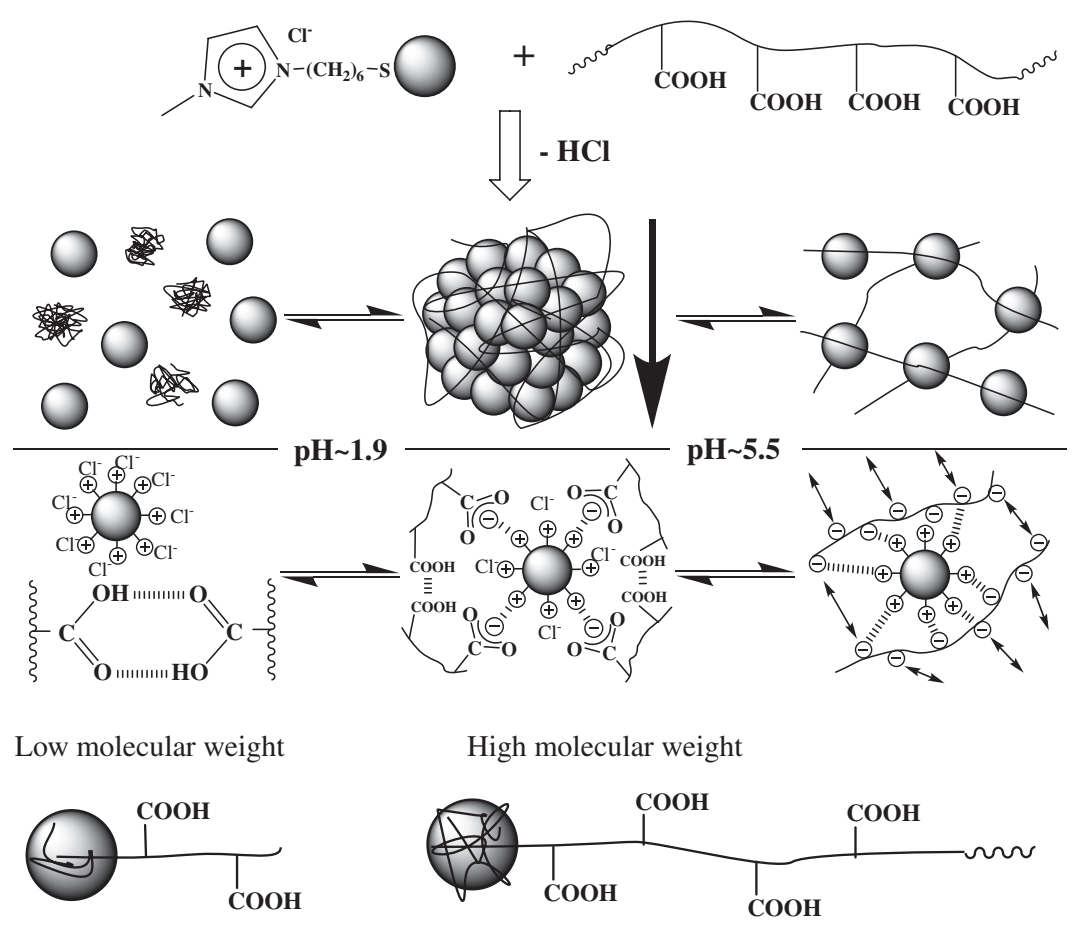

Figure 6. Proposed mechanism of the flocculation and the $\mathrm{pH}$ responsive aggregation of MImCl-AuNP with PAA.

although the electrostatic interaction between the imidazolium cations and the carboxylate anions exists as ever, the gold nanoparticles ensure enough dispersions for redissolution, and become redissolved in keeping certain degrees of aggregates. A strong acid containing polymer may not show the $\mathrm{pH}$ responsive precipitation-redispersion phenomena. No precipitate was observed after addition of poly(styrenesulfonic acid) (PSSA, $M_{\mathrm{w}}=70000$ ) when an equal molar ratio of PSSA to the imidazolium cation as the case of PAA. A DLS measurement of the sample suggested the aggregated state with a diameter range of 60 to $80 \mathrm{~nm}$ and the size was nearly unchanged against various $\mathrm{pH}$ due to the strong acidity of PSSA.

\section{CONCLUSIONS}

We have demonstrated the $\mathrm{pH}$-responsive control of the colloidal dispersions of the gold nanoparticles by using the electrostatic interaction between the cationic gold nanoparticles and PAA. After the addition of PAA, the gold nanoparticles were precipitated by the electrostatic interaction between the imidazolium cations on the surface of the gold nanoparticles and the carboxylate anions of PAA. The precipitates were redissolved and well redispersed when the $\mathrm{pH}$ dropped below 1.9 and redissolved with forming aggregates when the $\mathrm{pH}$ rose above 5.5. The present study demonstrated that the nanoparticle-based flocculate materials can be applied for $\mathrm{pH}$-responsive control of the colloidal dispersions of gold nanoparticles.
Acknowledgment. This study is a part of Kyoto City Collaboration of Regional Entities for the Advancement of Technology Excellence of JST on basis of research results supported in part by grant-in aids for Scientific Researches (B) (No. 16310086), and the 21st century COE program COE for a United Approach to New Material Science, Kyoto University. We thank Professor T. Fukuda, Dr. M. Tsujii and Dr. S. Yamamoto (Institute of Chemical Research, Kyoto University) for the TEM micrographs.

We dedicate this article to the memory of the Late Emeritus Professor Yoshihiko Ito.

\section{REFERENCES}

1. G. Schmid, Chem. Rev., 92, 1709 (1992).

2. L. N. Lewis, Chem. Rev., 93, 2693 (1993).

3. M.-C. Daniel and D. Astruc, Chem. Rev., 104, 293 (2004).

4. K. Naka, H. Itoh, and Y. Chujo, Langmuir, 19, 5496 (2003).

5. H. Itoh, A. Tahara, K. Naka, and Y. Chujo, Langmuir, 20, 1972 (2004).

6. H. Itoh, K. Naka, and Y. Chujo, J. Am. Chem. Soc., 126, 3026 (2004).

7. Y. Shiraishi, D. Arakawa, and N. Toshima, Eur. Phys. J. E, 8, 377 (2002).

8. J. Simard, C. Briggs, A. K. Boal, and V. M. Rotello, Chem. Commun., 1943 (2000).

9. C.-H. Su, P.-L. Wu, and C.-S. Yeh, Bull. Chem. Soc. Jpn., 77, 189 (2004).

10. J.-H. Kim and T. R. Lee, Chem. Mater., 16, 3647 (2004).

11. P. R. Selvakannan, S. Mandel, S. Phadtare, R. Pasricha, and M. Sastry, Langmuir, 19, 3545 (2003). 
12. J. Dupont, R. F. de Souza, and P. A. Z. Suarez, Chem. Rev., 102, 3667 (2002).

13. J. H. Davis Jr. and P. A. Fox, Chem. Commun., 1209 (2003).

14. J. M. Crosthwaite, M. J. Muldoon, S. N. V. K. Aki, E. J. Maginn, and J. F. Brennecke, J. Phys. Chem. B, 110, 9354 (2006).

15. T. Yonezawa, S. Onoue, and N. Kimizuka, Chem. Lett., 31, 1172 (2002).

16. A. Larsson, C. Walldal, and S. Wall, Colloids Surf., A, 159, 65 (1999).

17. Z. Zhong, S. Patskovskyy, P. Bouvrette, J. H. T. Luong, and A. Gendanken, J. Phys. Chem. B, 108, 4046 (2004).

18. J. N. Cha, H. Birkedal, L. E. Euliss, M. H. Bartl, M. S.
Wong, T. J. Deming, and G. D. Stucky, J. Am. Chem. Soc., 125, 8285 (2003).

19. V. S. Murthy, J. N. Cha, G. D. Stucky, and M. S. Wong, J. Am. Chem. Soc., 126, 5292 (2004).

20. S. Ulrich, M. Seijo, A. Laguecir, and S. Stoll, J. Phys. Chem. B, 110, 20954 (2006).

21. A. Sehgal, Y. Lalatonne, J.-F. Berret, and M. Morvan, Langmuir, 21, 9359 (2005).

22. Y. M. Chen, S. Matsumoto, J. P. Gong, and Y. Osada, Macromolecules, 36, 8830 (2003).

23. S. Yusa, A. Sakakibara, T. Yamamoto, and Y. Morishima, Macromolecules, 35, 5243 (2002).

24. H. Zhang and Y. Ito, Langmuir, 17, 8336 (2001). 